This item was submitted to Loughborough's Research Repository by the author.

Items in Figshare are protected by copyright, with all rights reserved, unless otherwise indicated.

\title{
Rotary moulding of ceramic hollow wares
}

PLEASE CITE THE PUBLISHED VERSION

PUBLISHER

(C) Elsevier

VERSION

AM (Accepted Manuscript)

LICENCE

CC BY-NC-ND 4.0

REPOSITORY RECORD

Al-Dawery, I.A.H., J.G.P. Binner, G. Tari, P.R. Jackson, W.R. Murphy, and M. Kearns. 2009. "Rotary Moulding of Ceramic Hollow Wares". figshare. https://hdl.handle.net/2134/4117. 
This item was submitted to Loughborough's Institutional Repository (https://dspace.lboro.ac.uk/) by the author and is made available under the following Creative Commons Licence conditions.

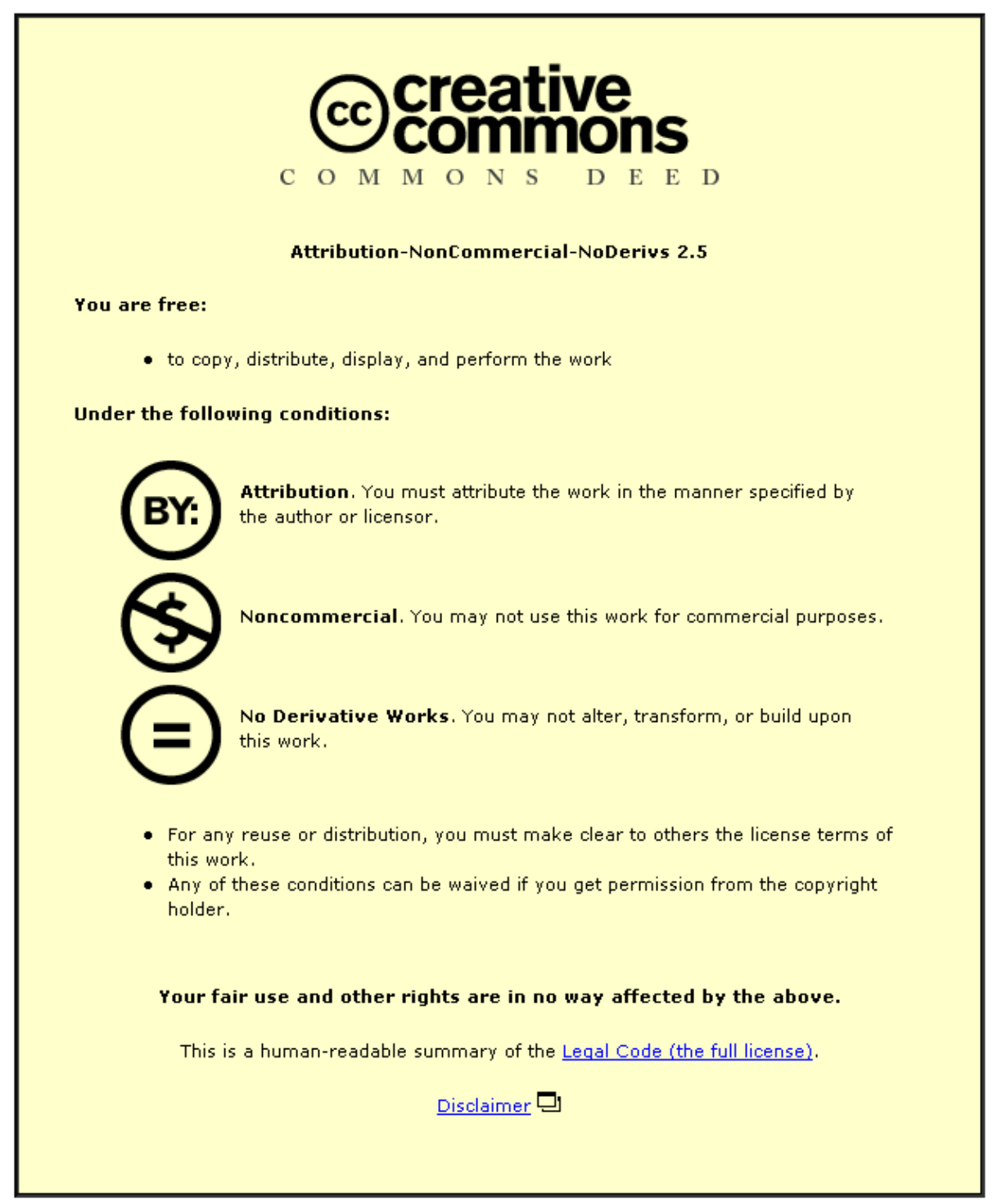

For the full text of this licence, please go to: http://creativecommons.org/licenses/by-nc-nd/2.5/ 


\title{
Rotary Moulding of Ceramic Hollow Wares
}

\author{
Al-Dawery, I.A.H*, Binner, J.G.P.*, Tari, G. ${ }^{+}$, Jackson, P.R. ${ }^{+}$, Murphy, W.R.* and Kearns, M.* \\ ${ }^{*}$ Loughborough University, Loughborough LEI 1 3TU, UK \\ ${ }^{+}$CERAM, Queens Road, Penkhull, Stoke-on-Trent, ST4 7LQ, UK \\ ${ }^{\#}$ Queen's University of Belfast, Belfast, BT9 SAH, UK
}

\begin{abstract}
A novel processing method for the fast and economic production of hollow ceramic components has been developed by combining in-situ coagulation moulding with a modified version of the technique of rotary moulding ${ }^{1}$, the latter being adapted from the polymer industry. The process was found to require a high solids content suspension, hence development work was performed in this direction though in the end a new, commercial suspension was utilised. Of the three forming routes of gel casting, direct coagulation casting and in-situ coagulation moulding, the latter was found to be the most promising for the new process of rotary moulding of ceramics. Due to the low value of clay-based ceramics, a new low cost coagulant was identified and the effect of lactone concentration and temperature on setting time determined.
\end{abstract}

Following substantial optimisation work, it was found that a two-speed approach to multi-axial rotation was the most successful; medium sized cream jugs could be produced in just 7 minutes. With respect to mould materials, the porous resin normally used for pressure casting of sanitary ware was found to be the best option, though since this is quite expensive conventional plaster-of-paris moulds were found to be a suitable material to enable companies, particularly SMEs, to become familiar with the technology whilst avoiding high costs for trials. The processed articles could be successfully fired and glazed using gas-fired kilns with no sign of any black cores.

Major advantages of the process include the ability to precisely calculate the amount of ceramic slip required, eliminating either slip wastage or the need to pour used slip back into the virgin material as currently happens with slip casting. In addition, since the precursor suspension has a very high solids content, the time and energy required to dry the green product and associated moulds has been considerably reduced.

Keywords: Rotational moulding, Gel-casting, Coagulation casting, Ceramics, Hollow ware

\section{Introduction}

The aim of this research work was to develop a new, sustainable ceramic production method that can replace slip casting and, in particular, the use of plaster moulds that go to landfill after as few as 40 casts. One particular goal was for the new process to be able to use potentially recyclable plastic or metal moulds having a lifetime of thousands of casts. This paper describes the key concept of the research, viz. the combination of either gel casting ${ }^{2}$, direct coagulation casting ${ }^{3}$ or in-situ coagulation moulding ${ }^{4}$ with an adapted version of the process of rotary moulding that is used in the plastics industry. The sanitaryware and tableware industries were used as exemplars. 
Rotary moulding has been used for the manufacture of a wide range of hollow plastic products, such as water tanks, kayaks and traffic cones, for more than forty years ${ }^{5}$. In the process, a precursor polymer powder is rotated in a heated mould, typically across 2 axes. As the powder starts to melt it spreads along the walls of the mould where it forms a skin; after cooling the cast part can be removed. In the current work, the polymer powder has been replaced with a ceramic suspension that undergoes a setting reaction during the rotation period; in-situ coagulation moulding (ICM) was found to be the best option.

$\mathrm{ICM}^{4}$ is based on the progressive destabilization of ceramic suspensions to form a viscoelastic solid within which the homogeneity of the initial dispersion is maintained. One route to achieving this is via the coagulation of electrosterically dispersed, high solids content ceramic suspensions as a result of the time dependent hydrolysis of carboxylic acid derivatives. Constraining this hydrolysis reaction within a non porous mould leads to the formation of high density green bodies. After drying, the ceramic components can be sintered without special debinding operations since only a small amount of organic additive is needed.

The new in-situ coagulation rotary moulding (ICRM) process has the potential to lead to faster production rates by a factor of 3 - 4 and reduced labour requirements by up to 30 - 40\% as well as substantial savings in drying energy, material purchase and factory space requirements. Although inevitably more expensive than the plaster moulds, it was hoped that the use of plastic or metal moulds would enable the use of CADCAM techniques for their production in the future, significantly increasing the flexibility of the manufacturing process and reducing the time needed to introduce new product shapes. As a consequence the whole manufacturing process for hollowware items might be made considerably less wasteful and more sustainable with product costs being significantly reduced, allowing the European ceramics industry to remain competitive and increase its market share.

\section{Experimental and Results}

\subsection{Optimisation of Suspension Compositions}

The first goal was to modify existing clay-based suspensions used to slip cast items so that they were suitable for either gel casting, direct coagulation casting or in-situ coagulation moulding, techniques that have been reviewed recently by Tari ${ }^{6}$. The aim was to determine which was best suited for the modified rotary moulding technique.

Following initial trials it became apparent that an extremely high solids content, ideally $>80$ wt $\%$, was critical for achieving solidification, rather than simply suspension thickening, from the relevant chemical reactions. To maximize the solids content, the zeta potential versus $\mathrm{pH}$ characteristics were initially measured for aqueous dispersions of each of the raw material powders used as a function of surfactant addition to determine the optimum levels of the latter so that the individual powder components all displayed similar zeta potential behaviour. Once these had been identified, the surfactants were added to each powder individually so that they could be combined at a fixed zeta potential value; this resulted in maximum deflocculation and hence low viscosity ${ }^{7}$. 
It is well known that increasing suspension viscosity increases the time required to de-air a slip; in the ceramic industry around $4 \%$ of production loss is currently associated with parts being rejected due to entrapped air bubbles and so anything that increases the viscosity of the initial slip is not desirable. Therefore limiting the suspension viscosity was a very important parameter in the development of the suspension.

Having optimised the zeta potential, the particle size distribution of the components was also investigated and optimised via grinding to maximize the solids loading further. In general, a broad particle size distribution allows the solids loading to be increased without a commensurate increase in viscosity ${ }^{8}$. Throughout the development work it was found to be essential to blunge the mixture for one hour in a shear mixer. Eventually, a suspension with a solids content of $>80 \mathrm{wt} \%$ was achieved whilst retaining a pourable consistency. The key steps were the understanding and control of the zeta potential and the optimisation of the raw material particle sizes.

Significant attention was given to keeping costs to a minimum since the traditional ceramics industry is very competitive (a major factor behind their support for the work) and hence works with extremely tight margins. Thus a number of options that could have been investigated for a purely scientific study were considered inappropriate, e.g. the introduction of especially fine powders as part of the particle size optimization stage they would have resulted in an increase in both production costs and health and safety issues in the factories. In addition, every component and additive had to be carefully considered to ensure that it did not result in thermal expansion differences between the body and the glaze, necessitating the development of a new glaze formulation.

A newly developed, commercial high solids content, low viscosity clay suspension with a density of $1.98 \mathrm{~kg} \mathrm{l}^{-1}$ was subsequently introduced to the research programme ${ }^{\mathrm{a}}$. In trials it outperformed the suspension developed above in terms of rheological behaviour and was also found to offer the additional advantage that more of the coagulation agent for the in-situ coagulation moulding process could be added, allowing acceleration of the coagulation reaction, which in turn reduced the time needed for this stage of the process (albeit at the expense of requiring a longer time for burnout, by a factor of 3 , at the start of the sintering schedule). Hence the commercial suspension was used for all the subsequent work.

\subsection{Consolidation Methods}

Work was focused on investigating the three different solidification techniques to determine which would be most suitable for rotary moulding. It rapidly became obvious that controlling the viscosity versus time behaviour as a function of temperature during solidification was crucial. Preliminary work focused on the formation of simple bars $(120 \times 12 \times 5 \mathrm{~mm})$, this was subsequently extended to cylinders using a very crude, single axis rotary moulding facility. It is believed that the study was the first time that any of the three techniques outlined in section 2.1 had been investigated with clay bodies.

\footnotetext{
${ }^{a}$ Developed by Imerys, Par Moor Centre, Par Moor Road, Par, Cornwall, PL24 2SQ, UK.
} 


\subsubsection{Gel-Casting}

The gel casting work, based on the use of the acrylamide monomers ${ }^{2}$, revealed that the order of mixing the components was very important and that continuous mixing of the slurry was vital to ensure homogeneity of properties in the final product, probably because of dealing with a multicomponent system. For reasons not yet understood, it was possible to gel cast clay bodies with a lower monomer content, but slightly more initiator and catalyst, compared to the gel casting of alumina ceramics.

Whilst it was possible to gel cast satisfactory clay bodies in $<1$ minute, there were significant problems associated with burning out the polymer phase. With an organic binder concentration of $\sim 5 \mathrm{wt} \%$, heating rates of only $1 / 2-1^{\circ} \mathrm{C} / \mathrm{min}$. up to $\sim 650^{\circ} \mathrm{C}$ were required and therefore the firing stage was very slow. In addition, the cost of the monomer, initiator and catalyst made the approach inherently expensive for relatively low cost items such as traditional ceramics. This approach was therefore not considered appropriate for the clay-based project in hand.

\subsubsection{Coagulation Casting}

The direct coagulation casting route is based on manipulation of the double layer, for example through enzyme catalysed reactions within electrostatically dispersed suspensions ${ }^{3}$, however all experiments were unsuccessful in terms of producing homogeneous ceramic bodies from the clay suspension and hence further work on this route was also abandoned. Fortunately, in contrast, the in-situ coagulation moulding (ICM) route ${ }^{4}$ was very successful in producing homogeneous bodies with as little as $1 \mathrm{wt} \%$ additions of the relevant organics.

A number of alternative coagulating agents for the ICM route were investigated; the most successful was based on the addition of lactones, organic chemicals that hydrolyse in water to form an acid. These were initially inert in the suspension but on hydrolysis, the speed of which could be controlled by the suspension temperature, they reduced the suspension $\mathrm{pH}$ causing the double layer around the particles to collapse and hence inducing solidification via increased particle-particle interactions.

However, the lactone used in previous work involving technical ceramics ${ }^{4}$ was considered too expensive for the traditional ceramics industry. Hence, in an attempt to keep the cost of the new process as low as possible, a new, low purity, low cost lactone that is widely used in the food industry, glucono-delta lactone, GDL, $\left(\mathrm{C}_{6} \mathrm{H}_{10} \mathrm{O}_{6}\right)$, was investigated and subsequently adopted as the coagulant of choice. With respect to burn out, TGA studies were performed on the as-received GDL lactone, after reaction with water and on a sample of the dried clay slip containing the lactone. The results, figure 1, indicated that the start of lactone degradation occurred at $180^{\circ} \mathrm{C}$ and that complete burn-out was achieved by $480^{\circ} \mathrm{C}$. 


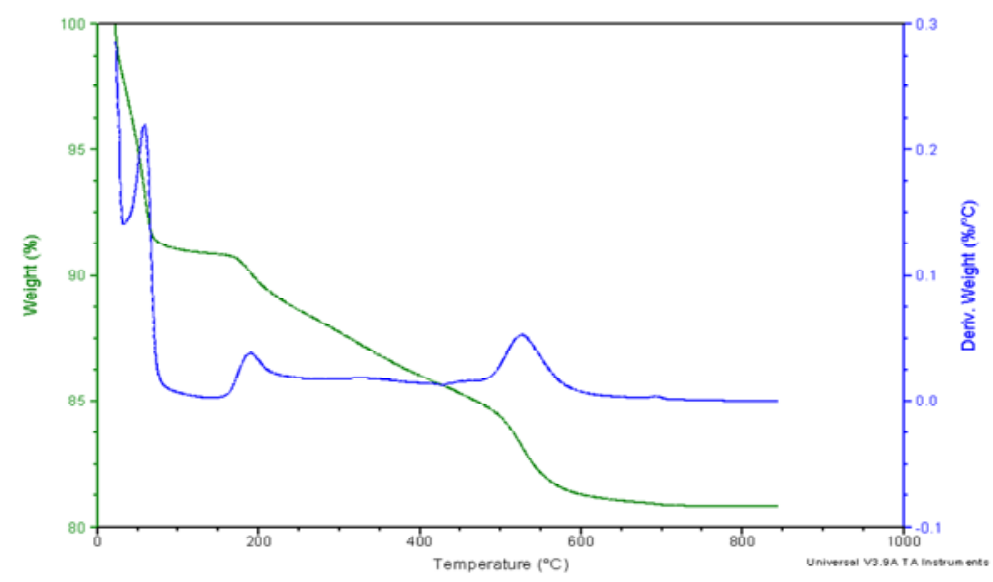

Fig. 1: TGA analysis of the clay slip with the lactone.

Subsequent experiments were designed to investigate the effect of the lactone concentration and processing temperature on the coagulation time, figures $2 \mathrm{a} \& \mathrm{~b}$. No attempt was made to optimize the level of lactone since the size, shape-complexity and wall thickness of the component determine the time required to ensure full and uniform coating of the inner walls of the mould during rotary moulding and hence the time required before the setting reaction increases the viscosity significantly. Hence the primary goal was to understand the influence of the different parameters so that they could be optimized on a case by case basis later in the programme. Nevertheless, it was ascertained that it was possible, by an appropriate combination of concentration and temperature, to achieving setting of the suspension in as little as 5 minutes.

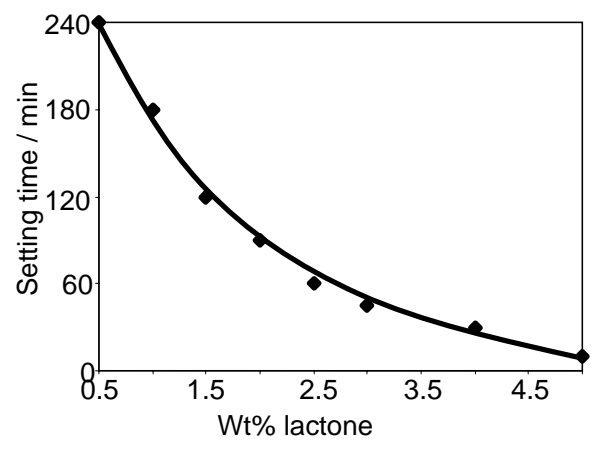

Fig. 2a: Effect of lactone concentration on setting time, at $25^{\circ} \mathrm{C}$.

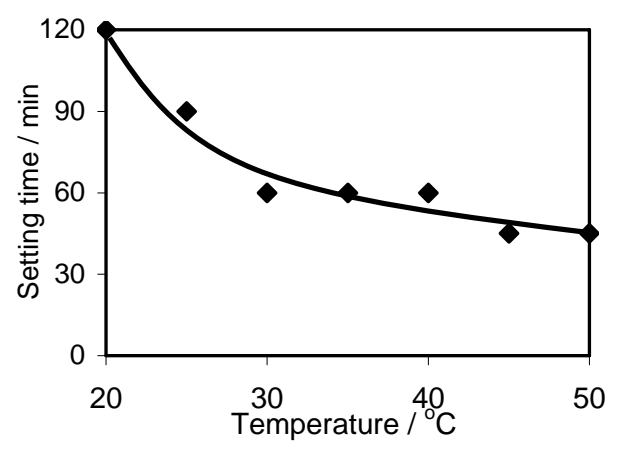

Fig. 2b: Effect of temperature on setting time, at 1 wt $\%$ lactone.

Successful firing trials were subsequently conducted using a gas-fired kiln at a heating rate of $4^{\circ} \mathrm{C} / \mathrm{min}(4-8$ times as fast as possible with gel casting). The lactone burnt out very cleanly during the firing cycle, avoiding the formation of a black core of unburnt carbon - a problem that can plague traditional ceramic ware produced with organic additives.

\subsection{Production of Hollow Bodies}


Existing lab-scale rotational moulding equipment normally used to form polymeric components was applied for use with ceramic slurries and trials were performed to investigate a wide range of processing parameters, including rotation speed and time, mould material, time interval after mixing the lactone into the slurry prior to rotation moulding, amount of slip used, atmosphere within the mould, the effect of de-airing the slip, demoulding and drying conditions. Many of these parameters affected each other, so a complex matrix of experiments was performed. Based on preliminary work, simple moulds made of aluminium were used for the initial trials; subsequently a range of mould materials and more complex moulds were investigated.

A heated-chamber approach was used to induce coagulation in the desired time period for closed surface objects such as figurines. However, for items such as teapots or sanitary ware, where holes leading into the interior void were required, a different approach based on internally heated moulds was investigated. The idea was to avoid heating the region of the mould where the hole was needed into the interior so that the slurry would not coagulate in this region. Results clearly demonstrated that this approach was not successful.

The results indicated that bodies could be successfully formed using a two-speed rotation process, figure 3 . Initially, a relatively high rotation speed was required which it was believed helped to compact the solidifying body against the inner mould wall. $20 \mathrm{rpm}$ for 2 minutes was typical for a small jug mould. However, after this initial period the speed of rotation could be decreased down to $10 \mathrm{rpm}$ whilst the rest of the suspension solidified. The required ratio of primary to secondary axes speeds was found to be entirely governed by the theology of the slip and the changes it undergoes as time progresses. This work led to the subsequent design and construction of a pilotscale rotary moulding facility, figure 4.
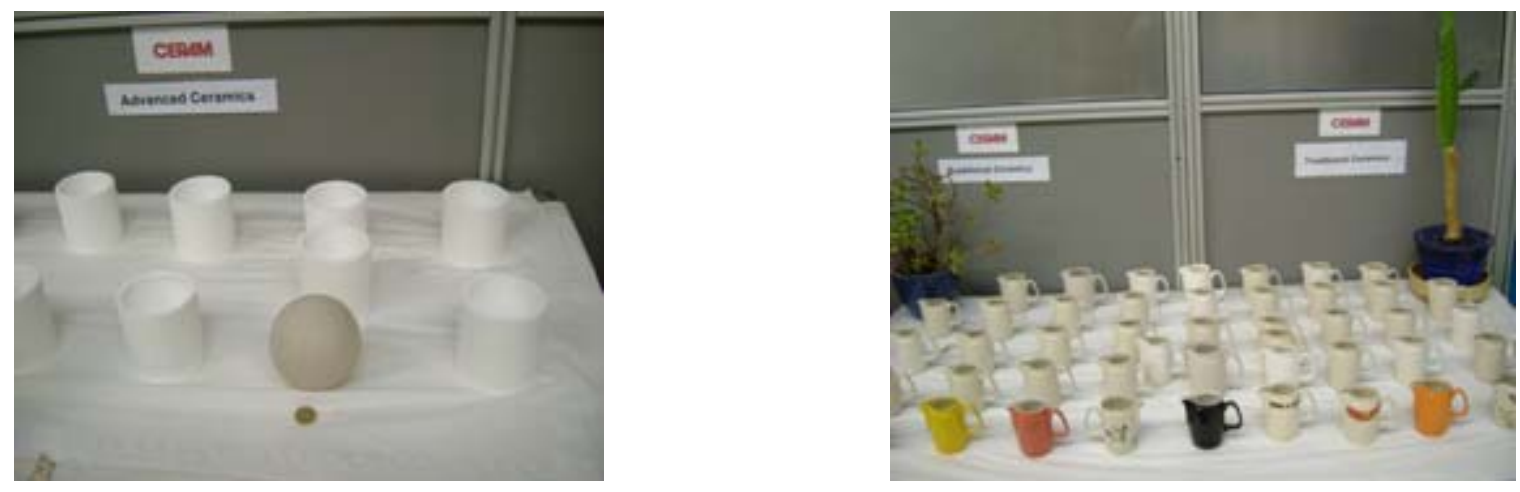

Fig. 3: Hollow ceramic items produced by the ICRM route.
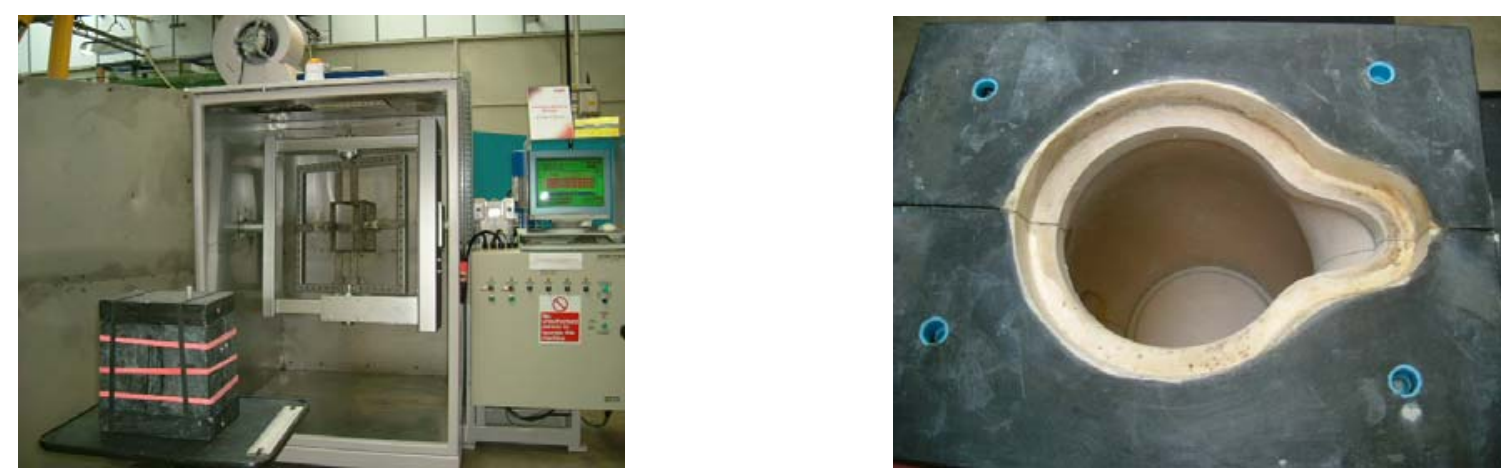

Fig. 4: Pilot plant machine and mould. 
Of all the mould materials examined, three were found to be successful; viz. a Teflon coated steel mould, a porous resin mould normally used for pressure casting of sanitary ware and conventional plaster-of-paris moulds. All three allowed the body to be cleanly and easily removed from the mould due to either suitable wetting characteristics (Teflon and resin) or the (very slight) dewatering of the compact (plaster-of-paris). Note that the porous resin mould did not de-water the suspension at all since the porosity was not capillary in nature, though it did aid the release of the cast piece by allowing compressed air to be used to push the piece away from the mould surface. It also allowed water to be used to clean the mould preventing clogging of the porosity.

In terms of the other processing parameters, it was observed that mixing in the lactone to the suspension immediately prior to the latter's introduction to the mould provided the best results; this could be easily done in an industrial setting and obviates any problems with suspension storage over long periods of time (e.g. weekend shutdowns). In addition, the amount of slip used could be precisely calculated for the wall thickness desired, eliminating either slip wastage or the need to pour used slip back into the virgin material as currently happens with slip casting.

Whilst the atmosphere used inside the mould had little effect, there was a need to keep the mould open, when not being rotated, to prevent the humidity in the mould becoming excessive and deleteriously affecting the coagulation reaction. Deairing of the slip followed standard industrial requirements, whilst de-moulding could be effected after typically $~ 7$ minutes, depending on the wall thickness and size of the cast. Note that due to the much higher solids content of the precursor slip, the time and energy required to dry the product was considerably reduced (by a factor of 3). Full results are being published elsewhere ${ }^{9}$

The mechanical strength of test bars was measured using 3-point flexural tests. The results indicated that both the green and fired strengths were similar to those of standard slip cast samples confirming that the new route was likely to yield a similar product quality.

\section{Conclusions}

A low cost, high solids content, low viscosity clay slip system has been developed, though this was subsequently replaced during the programme with an alternative, and also newly developed, commercial high solids content slip. The latter was used to investigate three different suspension setting technologies, vis. gel casting, direct coagulation casting and in-situ coagulation moulding for potential combination with a modified version of the polymer forming route known as rotary moulding. The in-situ coagulation moulding technique was found to be the best process on the basis of a) working with clay suspensions and b) having a minimal organic content and so allowing a shorter firing schedule. As part of the development work, a new low cost coagulant was identified and the effect of lactone concentration and temperature ascertained on setting time.

The optimum conditions for successful rotational moulding of small ceramic items were determined, initially using a machine designed for working with polymers but suitably modified and subsequently 
using a purpose designed and built pilot-scale facility. Parameters successfully optimised included rotation speeds; atmosphere, the need for de-airing, drying characteristics and mould materials. With regard to the latter, two materials in particular were identified. The porous resin mould material normally used for pressure casting of sanitary ware was found to be the best option, though since this is quite expensive conventional plaster-of-paris moulds were found to be a suitable material to enable companies, particularly SMEs, to become familiar with the technology whilst avoiding high costs for trials.

Bodies were successfully produced in a range of different shapes and sizes with a two-speed approach to multiaxial rotation being the most successful; medium sized cream jugs were produced in just 7 minutes. The processed articles could be successfully fired and glazed using gas-fired kilns with no sign of any black cores. The next stage of the project is the production of further demonstrator components, from within both the claybased and advanced ceramic sectors, so that commercialisation can be achieved in the near future.

\section{Acknowledgments}

The authors would like to acknowledge the financial support for this research work through the DTI grant No STI 1/1/060 and two EPSRC grants Nos GR-R59250-01 and GR-R59267-01 as well as the support of the industrial members of the research consortium.

\section{References}

1. Binner JGP, Al-Dawery IA, Tari G and Yan Y, Rotary casting technique. UK Patent application No. 0506349.0, March 2005.

2. Omatete 00, Janney MA and Strehlow RA., Gelcasting a new ceramic forming process Am. Ceram. Soc. Bull., 1991, 70 1641-49.

3. Graule TJ, Gauckler JL and Baader FH, Direct coagulation casting, a new green shaping technique, Part I: Processing principle. Ind. Ceram., 1996, 16 31-34.

4. Binner JGP, McDermott AM, Yin Y, Sambrook RM and Vaidhyanathan B, In-situ coagulation moulding: a new route for high quality, net shape ceramics. Cerana Int, 2006, 32 [1] 29-35.

5. Crawford, R.J, and Kearns, M.P., Practical Guide to Rotational Moulding. Rapra Technology Limited, 2003, ISBN 1-85957-387-8 (184 pages).

6. Tari G, Gelcasting of ceramics: a review, Am. Ceramic Society Bulletin, 2003, 82 [4] 43-46.

7. Tari G, Ferreira JMF and Lyckfeldt O, Influence of stabilisation mechanism and solid loading on colloidal processing of alumina, J. Eur. Ceram. Soc, 1998, 18 [5] 479-486.

8. Tari G, Ferreira JMF, Lyckfeldt $\mathrm{O}$ and Fonseca AT, Influence of particle size distribution on colloidal processing of alumina, J Eur. Ceram. Soc., 1998, 18 [3] 249-253.

9. Al-Dawery IA, Binner JGP, Tari G, Jackson P, Murphy R, Kearns M, Development of a new rotational moulding technology for sustainable ceramic production, to be submitted to Ceramics International. 